\title{
FACTORS INFLUENCING CLOUD COMPUTING ADOPTION IN SMALL AND MEDIUM ENTERPRISES
}

\author{
Haslinda Hassan, Mohd Herry Mohd Nasir, \\ Norhaiza Khairudin \& Iskandar Adon \\ Tunku Puteri Intan Safinaz School of Accountancy \\ Universiti Utara Malaysia, Malaysia
}

lynn@uum.edu.my; herry@uum.edu.my; norhaiza@uum.edu.my; iskan975@uum.edu.my

\begin{abstract}
Cloud computing offers information technology (IT) infrastructure, platform, and various applications via the Internet with minimum start-up cost, network access to a shared pool of configurable computing resources, and pay-per-use services. Although the potential for cloud computing is evident and much of the extant research has been carried out on cloud computing adoption, empirical studies on the factors that influence cloud computing adoption in the Malaysian Small and Medium Enterprises (SMEs) are, however, lacking. The objective of this study was to examine the factors that influence cloud computing adoption by the SMEs. We conducted a quantitative survey-based study to examine the relationship between perceived benefits, top management support, IT resources, external pressure, and cloud computing adoption. A free-form comment provided at the end of each section of the survey questionnaire was treated as qualitative data. We find that IT resources and external pressure significantly influence cloud computing adoption. Nonetheless, there is not enough evidence to support perceived benefits and top management support as significant factors of cloud computing adoption.
\end{abstract}

Keywords: Cloud computing, TOE framework, IOS model, SMEs. 


\section{INTRODUCTION}

With cloud computing, the world is literally at our fingertips! The emergence of cloud computing can elevate the competitiveness of businesses despite its potential to reduce the computing cost, accelerate the business operations, and optimize time to market (Abolfazli, Sanaei, Tabassi, Rosen, Gani, \& Khan, 2015). A strategic move must be seriously made by companies to grab a technology that allows them to transform business processes and prepare a new way of doing business. Certainly, cloud technology offers businesses pervasive storage, unlimited computing power, and mobility of business information over the Internet (Oliveira, Thomas, \& Espadanal, 2014) without the need to consider the information technology (IT) operation costs. With the delivery of low-cost or free applications anywhere on the Internet, cloud computing could be a promising prospect for Small and Medium Enterprises (SMEs) which have budgetary constraints.

A research conducted by Microsoft in 2011 reported that while larger Asian businesses are embracing cloud services, SMEs are still lagging behind (Galligan \& Mansor, 2011). SMEs have been argued to give very little attention to invest in IT infrastructure (Galligan \& Mansor, 2011) and face cost-related problems in employing staff with specialized computer expertise, hence, need to rely on outside resources (Igbaria, Zinatelli, Cragg, \& Cavaye, 1997). Consequently, the Malaysian government, through the Multimedia Development Corporation (MDeC), has urged the SMEs to change their mindset to adopt cloud computing by providing them a 6-month subscription fee rebate or up to RM1,500 of the total subscription fee for any software as a service (SaaS) solution from any Multimedia Super Corridor (MSC) Malaysia Status companies.

Although the potential for cloud computing is evident and much of the extant research has been carried out on cloud computing adoption, empirical studies on the factors that influence cloud computing adoption in the Malaysian SMEs are, however, lacking. This paper aims to contribute to a growing body of research on cloud computing by studying the factors that influence cloud computing adoption in the SMEs. To our knowledge, this study is the first attempt that advances the knowledge on the factors that influence cloud computing adoption in organizations, especially in the context of Malaysian SMEs. The empirical finding of the study is expected to provide insightful information for the policymakers in Malaysia, such as the MDeC, National IT Agenda (NITA), and SME Corp. Malaysia, to decide appropriate policies and economic incentives, legislative measures, and awareness-raising initiatives. Building on the Technology-Organization-Environment (TOE) framework (Tornatzky \& Fleischer, 1990) and the Inter-organizational System 
(IOS) model (Iacovou, Benbasat, \& Dexter, 1995), the study's findings may contribute to an understanding of the factors that influence SMEs' perceptions of cloud computing and may lead to further inquiry in this field.

The rest of the paper is organized as follows: In the next section, the literature on cloud computing is reviewed. In the third section, the research model and the hypotheses are described. The fourth section, methodology, describes in detail the survey instrument, unit of analysis, participants, data collection procedure, and measures. The fifth section discusses the data analysis technique, findings, and its interpretations. The conclusion, limitations, and suggestions for further research are provided in the final section.

\section{LITERATURE REVIEW}

The term, 'cloud computing', first emerged in the early 20th century as a commercial web service that allows small companies to have a platform to run their business applications from their own personal computers. The National Institute of Standards and Technology (NIST) defines cloud computing as "...a model for enabling ubiquitous, convenient, on-demand network access to a shared pool of configurable computing resources (e.g. networks, servers, storage, applications and services) that can be rapidly provisioned and released with minimal management effort or service provider interaction" (Mell \& Grance, 2009). Since then, various definitions have emerged to fit the various aims of studies on cloud computing. Nonetheless, these definitions revolve around the main characteristics of cloud computing, which include on-demand self-services, broad network access, resource pooling, rapid elasticity, and measured service (Mell \& Grance, 2009). Our study uses the cloud computing definition which focuses on services offered by data center providers for both application services and system software and hardware (Armbrust et al., 2010).

Cloud services denote various layers of the cloud computing architecture, including infrastructure as a service (IaaS), platform as a service (PaaS), and SaaS. Iaa refers to the basic level of cloud services that deliver infrastructure services to customers over a network; Paa offers online access to all the resources that are required to build an application; while Saa provides users a piece of software over a network (Gangwar, Date, \& Ramaswamy, 2015). Recent studies have shown that cloud for end-user services, such as e-mail or office applications, is increasingly being adopted by the organizations for daily business activities, which create both opportunities as well as challenges (Alshamaila, Papagiannidis, \& Li, 2013). A point to note is that cloud computing has unique characteristics compared to other IT innovations in 
terms of its customer targets (could be small, medium or large organizations), its interoperability (quality of services), its pricing mechanism (pay-as-need), and its delivery models (public, private or hybrid cloud) (Hsu, Ray, \& LiHsieh, 2014). This undoubtedly has triggered SMEs, which have limited human resources and finance, to grab the opportunity to 'outsource' their IT applications to keep their businesses competitive.

A study claims that in terms of readiness to adopt cloud computing, Malaysia is ranked 13th among 24 countries around the world and 8th among the ASEAN countries (Alliance, 2013) with the expectation that cost of injection will grow from USD43 million in 2013 to USD900 million in 2020 (Abolfazli et al., 2015). According to the Asia Cloud Computing Association (2015), Malaysian SMEs are ranked 11th out of 14 countries based on five pillars: size and attractiveness of the addressable market, capability and suitability of the economy as an early adopter of SME cloud-based tools, the existing and nascent demand drivers in the market, the relative affordability of those tools in the economy, and the levels of existing government and financial support for SMEs, IT programs and cloud computing adoption, as indices of cloud computing attractiveness among Asia-Pacific SMEs.

The proliferation of cloud computing has attracted the interest of many researchers to investigate its adoption in organizations globally. This includes the Asia-Pacific region (Gangwar et al., 2015; Gupta, Seetharaman, \& Raj, 2013; Hsu et al., 2014; Low, Chen, \& Wu, 2011; Yigitbasioglu, 2014; Yigitbasioglu, 2015), Europe (Gutierrez, Boukrami, \& Lumsden, 2015; Oliveira et al., 2014), and North America (Cegielski, Jones-Farmer, Wu, \& Hazen, 2012). Nonetheless, empirical studies on the factors that influence cloud computing adoption in organizations, especially in the context of Malaysian SMEs, are however, lacking. Our study addresses this gap.

Literature review witnessed that a few studies on cloud computing adoption in organizations used different adoption frameworks such as the TOE framework (see, for example, Hsu et al., 2014), the technology acceptance model (TAM)TOE (Gangwar et al., 2015), diffusion of innovation (DOI)-TOE (Oliveira et al., 2014), the institutional theory (Yigitbasioglu, 2015), the transaction cost theory (Yigitbasioglu, 2014), and the information processing theory (Cegielski et al., 2012). No specific theory, however, was used by Gupta et al. (2013). Most of these studies focused on both small and large companies in more than one industry, with the exception of Gupta et al. (2013) which emphasized on the SMEs only; while Low et al. (2011) focused on a single industry (i.e. hightech industry). In addition, the studies recognized the relevance of perceived benefits (relative advantage), complexity, and business concerns (from the technological context); top management support, technology readiness, 
organization size, and inter-organizational uncertainty (from the organizational context); external pressure, perceived vendor opportunism, and environmental uncertainty (from the environmental context) to cloud computing adoption in organizations. However, in the context of small organizations, Iacovou et al. (1995) suggested that IT innovations are being influenced by three main factors, namely perceived benefits (due to the limited impact that IT has on small organizations), organizational readiness (due to the low levels of IT sophistication and resource availability of small organizations), and external pressure (due to the weak market positions of small organizations and the network nature of the technology). Following Iacovou et al. (1995), we used these factors in this study. As the role of top management support to cloud computing adoption has been proven important in most of the existing studies on cloud computing adoption (see, for example, Yigitbasioglu, 2015), we introduced this factor as one of the organizational factors. The exclusion of other factors, such as complexity, in this study does not indicate that these factors are not relevant to cloud computing; these factors could be, however, considered for further research in this area.

Prior studies have simply measured cloud computing adoption by the intention to use cloud computing (see, for example, Cegielski et al., 2012; Gangwar et al., 2015; Yigitbasioglu, 2014) or as a binary variable (Gutierrez et al., 2015; Low et al., 2011). Money and Turner (2005) argued that the intention to use the technology does not lead to adoption or use. The binary measure (e.g. adopt or not adopt), on the other hand, does not capture salient variations in organizational behavior with respect to IT (Zhu, Dong, Xu, \& Kraemer, 2006). Our study addresses this gap by measuring the cloud computing adoption using a range of cloud-based technologies in an organization (with a 7-point Likert scale ranging from "not used at all" to "used very extensively"), hence, offering more variability in the overall measure.

\section{RESEARCH MODEL AND HYPOTHESES}

Based on the work of Tornatzky and Fleischer (1990) and Iacovou et al.(1995), a perception-based model for cloud computing adoption using a TOE framework was developed and is depicted in Figure 1. Tornatzky and Fleischer (1990), via their TOE framework, suggested that the process by which an organization adopts and implements technological innovations, is influenced by the factors from the technological $(\mathrm{T})$, organizational $(\mathrm{O})$, and environmental $(\mathrm{E})$ contexts. The Iacovou et al. (1995) model, on the other hand, analyses the interorganizational systems' (IOSs) characteristics that influence organizations to adopt IT innovations based on three factors: perceived benefits, organizational readiness, and external pressure. 


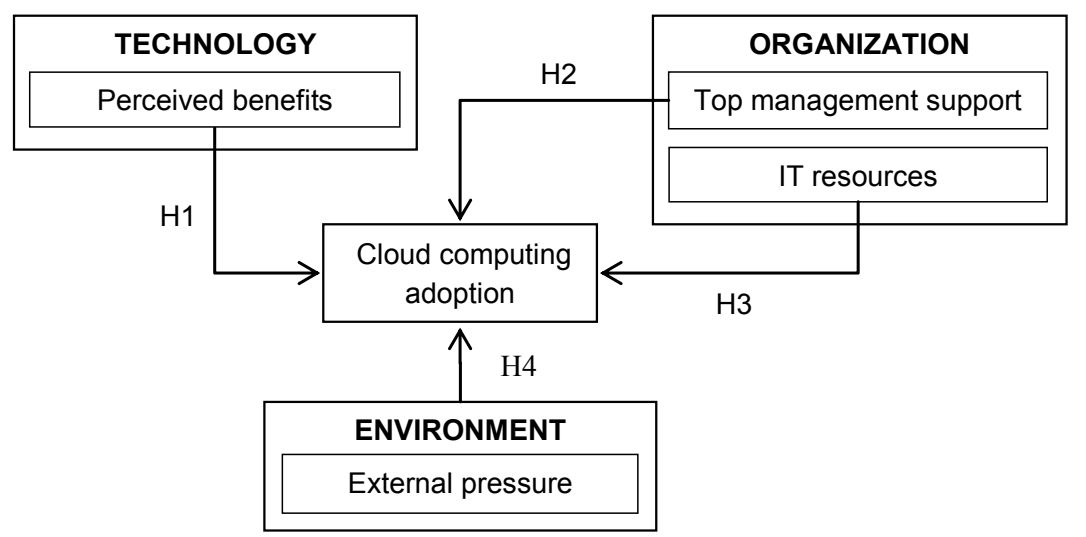

Figure 1. Research model.

According to Raymond (2001), a combination of theories is needed when the adoption decision is linked (e.g. when imposed by a business partner), and when innovations are adopted by the organization (as opposed to being adopted autonomously by individuals). Therefore, we have advocated the need of integrating the TOE framework and Iacovou et al.'s model so that the predictive power of the resulting model can be improved. The combination of Iacovou et al.'s model and TOE seems popular and has been widely used by prior studies (Oliveira \& Martins, 2010).

\section{Technological Context}

Technological context refers to technologies that are relevant to the organization (Tomatzky \& Fleischer, 1990). Perceived benefits have been frequently cited as one of the major drivers of cloud computing adoption in organizations (see, for example, Hsu et al., 2014).

Perceived Benefits. Many researchers have measured perceived benefits as the anticipated benefits of technological innovation (Oliveira \& Martins, 2010). The benefits of cloud computing include customization, ease of data analysis, reduction of deployment time, IT, and IT employee costs, and ubiquitous access (Hsu et al., 2014). Low et al. (2011) asserted that cloud computing adoption may increase business communications speed, improve efficiency in inter- organization coordination, create better customer communications, and enhance access to market information mobilization. Hassan and Ismail (2015) discovered that cloud computing leads to strategic (e.g. helping organizations 
to create competitive advantage and establishing useful links with other organizations) and informational (e.g. easier access to information and improve information accuracy) benefits. With cloud computing, the installation and the maintenance of the information system are no longer under the responsibility of the organization as they are now being managed by the cloud computing vendor, thereby reducing IT-related costs to the organization. Based on this reasoning, cloud computing should provide a marked advantage to adopters. Hence, the argument above leads to the following hypothesis:

H1: Perceived benefits are positively related to cloud computing adoption.

\section{Organizational Context}

Organizational context refers to an organization's size, scope, and the amount of slack resources available internally, or other internal aspects of the organization (Tornatzky \& Fleischer, 1990). In our study, the organizational factors covered are top management support and IT resources.

Top Management Support. Support from top management is one of the main challenges in innovation adoption. This is due to the fact that the willingness of the top management to approve sufficient financial investment, human resources, and technological competencies, is crucial for enabling the adoption. Generally, it is important for top management - as the organization's decisionmakers - to understand the benefits of the innovation and how it can create competitiveness (Alshamaila et al., 2013). Prior studies (see, for example, Oliveira et al., 2014) have argued the importance of top management support to ensure that resources needed to adopt a technology or to expand its use, are available. Lack of top management support would therefore, lead to the failure of implementation (Grandon \& Pearson, 2004).

Premkumar (2003) refers to top management support as the extent of commitment and resource support given by the top management. The role of the top management in the successful adoption and diffusion of IT has long been recognized. Yigitbasioglu (2015), for instance, found top management support as the most important factor in influencing cloud computing adoption. Hence, it is hypothesized that organizations are more likely to adopt cloud computing when the top management provides support.

H2: Top management support is positively related to cloud computing adoption. 
IT Resources refer to the organization's readiness in terms of the technology resources it has for innovation adoption. Technology readiness is relevant for determining the adoption of innovation in an organization and is considered influential, either as a facilitator or an inhibitor (Oliveira, et al., 2014; Tornatzky \& Fleischer, 1990). Prior studies have suggested that technology infrastructure can establish an important platform on which technology can be implemented or developed (Iacovou et al., 1995).

Organizations, which have reached a level of sophistication in terms of technological readiness, are usually seen to be highly integrated in terms of computerized processes and are considered as better prepared to adopt IT innovation; hence they can attain greater benefits (Gangwar et al., 2015; Iacovou, et al., 1995). It is therefore, hypothesized that organizations are more likely to adopt cloud computing when there is a higher availability of IT resources in the organization.

H3: IT resources are positively related to cloud computing adoption.

\section{Environmental Context}

Environmental context refers to the external environment where the organization operates. The environmental factors can be either the constraints or the enablers for innovation adoption (Hsu et al., 2014). The only environmental factor covered in this study is external pressure.

External Pressure refers to pressures faced by organizations from their competitors within the industry (Oliveira et al., 2014). Researchers have suggested that the force from intense competition within the organization's industry is deemed as an important determinant for innovation adoption. Low et al. (2011), for instance, contended that organizations that feel the pressure from the rapid technological changes and the external pressure due to these changes, tend to adopt the new technologies in order to maintain their competitiveness. Competition within the industry has been perceived to positively influence innovation adoption, particularly when it is strategically necessary to adopt the new technology in order to compete within the industry. In cloud computing adoption, this seems to be relevant where organizations that are in the advanced stage of implementing cloud computing tend to obtain benefits in terms of competitive advantages and business agility (Gangwar et al., 2015). Hence, it is hypothesized that:

H4: External pressure is positively related to cloud computing adoption. 


\section{METHODOLOGY}

This study was a quantitative study, where a cross-sectional survey questionnaire was used for data collection. Quantitative data are primarily used for hypotheses testing. However, an open-ended question was provided to the respondents at the end of each section of the questionnaire to allow them to provide explanations or to comment on their answers. The data obtained from this free-form comments were treated as qualitative. Qualitative data were used to interpret the results of the hypotheses testing, hence, playing a supplementary role.

\section{Pretesting Survey Instrument}

Prior to data collection, the questionnaire was refined via experts' reviews and pre-testing. This stage involved 10 academicians with IS background and three SME managers. In addition to reviewing the content and the scope of the questionnaire, pre-testing was carried out to determine the strengths and weaknesses of the questionnaire in terms of question format, wording and order.

\section{Unit of Analysis}

The unit of analysis was the organization, namely SMEs in Malaysia. According to the SME Annual Report 2013/14, SMEs play a significant role in Malaysia's economic development and make up $99 \%$ of the total business establishment in Malaysia. From January 1, 2014, an enterprise was classified as an SME based on the total sales turnover generated by a business in a year or the number of people a business employs. There are two main industrial sectors in Malaysia, namely manufacturing, and services and other sectors. A manufacturing company is deemed as an SME if its annual sales turnover does not exceed RM50 million or its full-time employees do not exceed 200. SMEs in the services or other sectors, on the other hand, have annual sales turnover of less than RM20 million or employees not exceeding 75. Enterprises from both the manufacturing, and the services and other sectors are covered in this study.

\section{Participants}

The target number of respondents was senior managers of the SMEs, including owners and senior executives. Managers were considered as the most appropriate key informants in this study as they were well positioned in 
the organization and knew their organization's IT resources and technological environment (Cohen, Mou, \& Trope, 2014). Nonetheless, in the absence of senior managers, eligible respondents who understood the current IT operations and the overall business activities of the organization were allowed to take part in the survey.

\section{Data Collection Procedure}

The questionnaires were personally administered to respondents at multiple workshops participated by the SMEs. Convenience sampling, where subjects were selected based on their convenient accessibility, was used for sample selection. However, convenience sampling suffers from sampling bias because the sample does not represent the population (Hair, Money, Page, \& Samouel, 2007). Being aware of this drawback, we do not claim generalization of any findings of the survey.

Atotal of 343 questionnaires were distributed at the workshops. The respondents were informed about the purpose of the study and the confidentiality of their responses. Out of the 343, questionnaires 140 responses were received. Eight responses were excluded due to excessive missing values. Only 132 responses were used for further analysis. The usable response rate was, 38\%. Most of the organizations were operating in the services and other sectors $(65 \%)$, while only $31 \%$ were in the manufacturing sector. Of these, $58 \%$ were Sdn. Bhd. companies and $36 \%$ were partnerships or sole traders. The majority of the organizations had less than 75 full-time employees (91\%) and $45 \%$ were without IT employees. Most of them (65\%) had an annual sales turnover of less than RM1 million.

\section{Measures}

All constructs and their indicators were adapted from previously validated measures and developed based on existing literature (see Table 1). Details of the indicators are listed in Table 2. These indicators are seven-point Likert scales, anchored by "strongly disagree" and "strongly agree" for factors affecting cloud computing adoption, and "not used at all" and "used very extensively" for cloud computing adoption.

Cloud computing adoption is measured by using a range of cloud-based technologies in an organization. Following Choudhary and Vithayathil (2013), these technologies were classified into three categories: e-mail (e.g. 
Gmail), raw storage (e.g. Dropbox), and raw computing (e.g. Amazon EC2). At the end of each category of the cloud-based technology, a blank space was provided for the respondents to indicate other cloud-based technologies not specifically listed in the questionnaire. All constructs were based on reflective multi-item scales.

Table 1

Constructs and their Sources

\begin{tabular}{cll}
\hline \multicolumn{1}{c}{ Context } & \multicolumn{1}{c}{ Construct } & \multicolumn{1}{c}{ Source } \\
\hline Technology & Perceived benefits (PB) & Oliveira et al. (2014) \\
Organization & Top management support (TMS) & Lian, Yen, \& Wang (2014); \\
& & Low et al. (2011); Oliveira et \\
& & al. (2014) \\
& IT resources (ITR) & Oliveira et al. (2014) \\
Environment & External pressure (EP) & Low et al. (2011); Oliveira et \\
& & al. (2014) \\
\hline
\end{tabular}

\section{FINDING AND DISCUSSION}

Partial Least Squares (PLS) (via SmartPLS version 3.0 software) was used for statistical analysis. PLS is a structural equation modelling (SEM) technique that allows testing and estimating causal relationships among multiple independent and dependent constructs simultaneously. A two-step approach was used in the analysis: assessment of the measurement model and assessment of the structural model.

\section{Assessment of the Measurement Model}

The measurement model refers to the relationship between a construct and its measures. Testing the measurement model covers construct reliability, convergent validity, and discriminant validity. Construct reliability is evaluated using the composite reliability scores ranging from 0 (indicating completely unreliable) to 1 (indicating perfectly reliable). The constructs are deemed adequate when the composite reliability scores are above the recommended cut-off of .70 (Chin, 1998). As shown in Table 2, the composite reliability scores exceed .70, and thus, the model is considered reliable. 
Table 2

Item Loadings for Indicators of Latent Constructs

\begin{tabular}{|c|c|c|c|c|c|}
\hline Construct & & Item & Loading & $\mathrm{CR}$ & AVE \\
\hline \multirow[t]{6}{*}{$\begin{array}{l}\text { Perceived } \\
\text { benefits (PB) }\end{array}$} & PB1 & $\begin{array}{l}\text { Cloud computing adoption } \\
\text { improves customer relations. }\end{array}$ & .869 & .968 & .834 \\
\hline & PB2 & $\begin{array}{l}\text { Cloud computing adoption } \\
\text { provides better products or } \\
\text { services to customers. }\end{array}$ & .868 & & \\
\hline & PB3 & $\begin{array}{l}\text { Cloud computing adoption } \\
\text { reduces operating costs. }\end{array}$ & .949 & & \\
\hline & PB4 & $\begin{array}{l}\text { Cloud computing adoption } \\
\text { avoids the need to increase the } \\
\text { workforce. }\end{array}$ & .927 & & \\
\hline & PB5 & $\begin{array}{l}\text { Cloud computing adoption } \\
\text { increases the organization's } \\
\text { returns on financial assets. }\end{array}$ & .940 & & \\
\hline & PB6 & $\begin{array}{l}\text { Cloud computing adoption } \\
\text { enhances employee productivity. }\end{array}$ & .923 & & \\
\hline \multirow[t]{7}{*}{$\begin{array}{l}\text { Top management } \\
\text { support (TMS) }\end{array}$} & TMS1 & $\begin{array}{l}\text { Top management is likely } \\
\text { to invest funds in cloud } \\
\text { computing. }\end{array}$ & .650 & .942 & .701 \\
\hline & TMS2 & $\begin{array}{l}\text { Top management is interested } \\
\text { in using cloud computing } \\
\text { in order to gain competitive } \\
\text { advantage. }\end{array}$ & .868 & & \\
\hline & TMS3 & $\begin{array}{l}\text { Top management supports } \\
\text { the implementation of cloud } \\
\text { computing. }\end{array}$ & .860 & & \\
\hline & TMS4 & $\begin{array}{l}\text { Top management provides } \\
\text { strong leadership and engages } \\
\text { in the process when it comes to } \\
\text { information systems. }\end{array}$ & .864 & & \\
\hline & TMS5 & $\begin{array}{l}\text { Top management is willing to } \\
\text { take risks in the use of cloud } \\
\text { computing. }\end{array}$ & .839 & & \\
\hline & TMS6 & $\begin{array}{l}\text { Top management provides } \\
\text { resources to adopt cloud } \\
\text { computing. }\end{array}$ & .882 & & \\
\hline & TMS7 & $\begin{array}{l}\text { Top management understands } \\
\text { the benefits of cloud computing. }\end{array}$ & .874 & & \\
\hline
\end{tabular}

(continued) 


\begin{tabular}{|c|c|c|c|c|c|}
\hline Construct & & Item & Loading & CR & AVE \\
\hline \multirow[t]{2}{*}{$\begin{array}{l}\text { IT resources } \\
\text { (ITR) }\end{array}$} & ITR1 & $\begin{array}{l}\text { The use of cloud computing } \\
\text { is compatible with existing } \\
\text { hardware and software in our } \\
\text { organization. }\end{array}$ & .717 & .787 & .652 \\
\hline & ITR2 & $\begin{array}{l}\text { The technology infrastructure } \\
\text { of our organization is } \\
\text { available for supporting cloud } \\
\text { computing. }\end{array}$ & .889 & & \\
\hline \multirow[t]{6}{*}{$\begin{array}{l}\text { External pressure } \\
\text { (EP) }\end{array}$} & EP1 & $\begin{array}{l}\text { Our organization would have } \\
\text { experienced a competitive } \\
\text { disadvantage if cloud } \\
\text { computing had not been used. }\end{array}$ & .793 & .942 & .732 \\
\hline & EP2 & $\begin{array}{l}\text { Our organization thinks that } \\
\text { cloud computing has an } \\
\text { influence on competition in our } \\
\text { industry. }\end{array}$ & .855 & & \\
\hline & EP3 & $\begin{array}{l}\text { Our organization is under } \\
\text { pressure from competitors to } \\
\text { use cloud computing. }\end{array}$ & .876 & & \\
\hline & EP4 & $\begin{array}{l}\text { Some of our competitors have } \\
\text { already started using cloud } \\
\text { computing. }\end{array}$ & .893 & & \\
\hline & EP5 & $\begin{array}{l}\text { Using cloud computing helps } \\
\text { our organization to compete } \\
\text { better with our competitors. }\end{array}$ & .872 & & \\
\hline & EP6 & $\begin{array}{l}\text { Our organization feels it is a } \\
\text { strategic necessity to use cloud } \\
\text { computing to compete in the } \\
\text { marketplace. }\end{array}$ & .840 & & \\
\hline \multirow{3}{*}{$\begin{array}{l}\text { Cloud computing } \\
\text { adoption (CC) }\end{array}$} & $\mathrm{CC} 1$ & E-mail (e.g. Gmail) & 650 & .848 & .654 \\
\hline & $\mathrm{CC} 2$ & Raw storage (e.g. Dropbox) & .888 & & \\
\hline & $\mathrm{CC} 3$ & $\begin{array}{l}\text { Raw computing (e.g. Amazon } \\
\text { EC2) }\end{array}$ & .867 & & \\
\hline
\end{tabular}

Convergent validity refers to the extent to which the indicators of a measure correlate. Convergent validity is examined through item loadings where a cutoff value of 0.6 suggests that they measure the same construct (Chin, 1998). All items shown in Table 2 loaded higher than the threshold value of .60. The average variance extracted (AVE) value of each construct loaded higher than the threshold value of .50, as recommended by Fornell and Larcker (1981), 
hence suggesting convergent validity. All constructs in the model had adequate reliability and convergent validity. None of the items was, therefore, removed from the dataset.

Table 3

Discriminant Validity: Fornell-Larcker Criterion

\begin{tabular}{lccccc}
\hline & CC & EP & ITR & PB & TMS \\
\hline Cloud computing adoption (CC) & $\mathbf{. 8 0 9}$ & & & & \\
External pressure (EP) & .257 & $\mathbf{. 8 5 5}$ & & & \\
IT resources (ITR) & .266 & .526 & $\mathbf{. 8 0 7}$ & & \\
Perceived benefits (PB) & .106 & .401 & .435 & $\mathbf{. 9 1 3}$ & \\
Top management support (TMS) & .181 & .592 & .707 & .553 & $\mathbf{. 8 3 7}$ \\
\hline
\end{tabular}

Note. Numbers in bold denote the square root of the average variance extracted (AVE).

Discriminant validity indicates that the constructs are distinct. The FornellLarcker criterion is used to evaluate discriminant validity where the square root of AVE is examined and all the inter-construct correlations are compared. As shown in Table 3, the square roots of the AVE of each construct are greater than the cross-correlations between them (Fornell \& Larcker, 1981), thereby suggesting discriminant validity.

\section{Assessment of the Structural Model}

The structural model refers to the relationship between the constructs. Testing the structural model covers path coefficients (the strength and the sign of the theoretical relationships), hypotheses testing, and variance explained by the independent variables. The hypotheses were tested by examining the path coefficients using a bootstrap procedure with 5,000 resamples (Hair, Black, Babin, \& Anderson, 2010).

Table 4

Hypotheses Testing

\begin{tabular}{llccccl}
\hline Hypothesis & Relationship & Beta $(\beta)$ & SE & t-value & p-value & \multicolumn{1}{c}{ Result } \\
\hline H1 & PB $\rightarrow$ CC & -.028 & .102 & .272 & .785 & Not supported \\
H2 & TMS $\rightarrow$ CC & -.086 & .136 & .630 & .528 & Not supported \\
H3 & ITR $\rightarrow$ CC & .237 & .116 & 2.044 & .041 & Supported* \\
H4 & EP $\rightarrow$ CC & .194 & .093 & 2.094 & .036 & Supported* \\
\hline
\end{tabular}

*Significant at $\mathrm{p}<.05$ 
The results of the structural model are summarized in Table 4. Out of the four hypotheses, two are supported: IT resources (H3) and external pressure (H4). Perceived benefits (H1) and top management support (H2), on the other hand, are found to be not significant. The variance explained is .10. Kline (2011) suggested that standardized path coefficients with values close to .10 or below should be interpreted as corresponding to small-effect sizes.

Perceived benefits do not affect cloud computing adoption $(\beta=-.028, \mathrm{p}=$ .785). H1 is, therefore, not supported. This finding is consistent with other cloud computing studies (Gutierrez et al., 2015). Despite the benefits of cloud computing, the technology would not have been adopted if the top management does not support the adoption. This is due to the insignificant result of top management support to cloud computing adoption in this study (see H2). Although cloud computing is not bound by place, time and infrastructure, the organization needs to partially administer these services, and partially maintain IT infrastructure (Gangwar et al., 2015). Investment in IT infrastructure, however, requires approval from the top management. In addition, the organization may also be concerned with hidden additional costs that might need to be paid by adopters should they have to customize the cloud solutions to fit their specific requirements (Gangwar et al., 2015). Therefore, perceived benefits are not seen as a significant factor. This finding may be supported by the following quotes from SMEs who took part in the survey:

"Although cloud applications are appropriate, however, we lack skilled workers to use the application as a whole."

"'Cloud-based' is dangerous and is likely to be compromised by Internet experts."

Surprisingly, top management support is found to be not significant in explaining cloud computing adoption among the SMEs $(\beta=-.086, \mathrm{p}=.528)$. $\mathrm{H} 2$ is, therefore, not supported. The finding contradicts prior studies done in this area, such as Lian et al. (2014) which identified the importance of top management support in deciding for cloud computing adoption in Taiwanese hospitals. Similarly, Low et al. (2011) found evidence of the effect of top management support on the adoption of cloud computing in high-tech industry in Taiwan. Nonetheless, different industries (SMEs in this study; hospitals in Lian et al., 2014; high-tech in Low et al., 2011) may have their own concerns with cloud computing adoption.

This finding indicates that top management support, in terms of securing the resources needed for technology adoption, evidently is not relevant 
to explain cloud computing adoption among the SMEs. The nature of the free cloud services software (i.e. public databases, such as Google Drive and Dropbox) may also justify the minimal requirements needed for top management approval, especially in terms of financial provision. In addition, top management support is no longer a driver as organizations are starting to adopt cloud computing services because of cheaper and more agile IT resources to support business growth (Gutierrez et al., 2015). This result can be further supported by the following quote from one of the SMEs:

\section{"There is no budget provision in that field as the business profit is flat only."}

Another SME remarked that, "Our company is not ready yet to use cloud as a whole and facing any of the risks".

The study provides empirical evidence that IT resources significantly and positively influence cloud computing adoption among the SMEs with a medium effect size $(\beta=.237, \mathrm{p}=.041)$, hence supporting H3. The results indicate that SMEs with higher levels of IT resources are more likely to adopt cloud computing. This is possibly because organizations with high IT resources are more familiar with the latest IT and keep up with dynamic IT trends (Hsu et al., 2014). In addition, the size of the IT department in small companies is obviously smaller, thereby making it easier for them to make changes in IT culture (Gangwar et al., 2015). The significance of IT resources to cloud computing adoption is consistent with the results found by prior studies on cloud computing adoption (see, for example, Gangwar et al., 2015; Hsu et al., 2014) and other innovation technologies (see, for example, Oliveira \& Martins, 2010). This result, however, contradicts several studies on cloud computing which have found that organizations with lower IT capability would have higher intention to adopt cloud computing (see, for example, Low et al., 2011).

Consistent with prior studies (Gangwar et al., 2015; Low et al., 2011), the path from external pressure to cloud computing adoption is significant $(\beta=$ $.194, \mathrm{p}=.036)$. This indicates that external pressure affects cloud computing adoption with a medium effect size. H4 is, therefore, supported. The finding implies that when organizations face strong competition, they tend to respond more quickly in the competitive environment. One of the SMEs asserted that,

\footnotetext{
"Pressure from competitors is strong in the use of cloud and if we are slow to act, we will be left behind."
} 


\section{CONCLUSION, LIMITATIONS, AND FURTHER RESEARCH}

The objective of this study was to examine factors that influence cloud computing adoption in Malaysian SMEs. Four factors identified from the literature are: perceived benefits - the benefits of using cloud computing (from the technological context); top management support - the extent of commitment and resource support given by the top management; IT resources - the organization's readiness in terms of technology resources it has for innovation adoption (from the organizational context); and external pressure - pressures faced by organizations from their competitors within the industry (from the environmental context).

Data were collected via survey questionnaires (quantitative) and freeform comments provided at the end of each section of the questionnaires (qualitative). Of the three TOE contexts, only factors from the organizational (i.e. IT resources) and environmental (i.e. external pressure) contexts are found to be significant to cloud computing adoption. Perceived benefits and top management support are, however, found to be not significant. The findings suggest that perceived benefits and top management support are not the two drivers for SMEs to move to cloud computing. Although cloud computing is perceived as bringing benefits to the SMEs, such as cutting down the organization's costs, SMEs with more IT resources and facing more pressure from the competitors are found to be more likely to adopt cloud computing. Further, the nature of the free cloud services software, such as Dropbox, that do not require support from top management, in terms of their financial commitment, may justify the irrelevance of top management support in cloud computing adoption.

The findings of the study may have implications for government agencies, such as the SME Corp. Malaysia and $\mathrm{MDeC}$, in promoting the use of cloud computing to the SMEs. The results suggest the importance for SMEs to possess adequate IT resources, such as hardware and software, to support cloud computing. The findings also can help SMEs to consider their IT investments when implementing cloud computing. For academia, this study provides a useful reference for future studies in this subject area, especially in the Malaysian context.

This study primarily focuses on cloud computing adoption in the Malaysian SMEs. The findings may, therefore, notbe representative of the otherpopulations as a whole and need to be interpreted with care. In addition, convenience sampling was used for the sample selection. Hence, bias in the method of 
selecting the subjects may exist. In future studies, this bias may be addressed with the use of targeted sampling. In addition, further studies may consider qualitative approaches, including interviews, to gain in-depth understanding of the factors that influence cloud computing adoption. Interviews can offer more detailed and richer explanations for the underlying factors. As cloud computing evolves into maturity, other factors (e.g. complexity) may also need to be considered for investigation in the future.

\section{ACKNOWLEDGMENTS}

The authors would like to thank Universiti Utara Malaysia and the Ministry of Higher Education Malaysia for financially supporting this research (FRGS/1/2014/SS05/UUM/02/29).

\section{REFERENCES}

Abolfazli, S., Sanaei, Z., Tabassi, A., Rosen, S., Gani, A., \& Khan, S.U. (2015). Cloud adoption in Malaysia: Trends, opportunities, and challenges IEEE Cloud Computing. 60-68.

Alliance, B. T. (2013). 2013 BSA global cloud computing scorecard. Retrieved from http://cloudscorecard.bsa.org/2013/assets/PDFs/BSA_ GlobalCloudScorecard2013.pdf

Alshamaila, Y., Papagiannidis, S., \& Li, F. (2013). Cloud computing adoption by SMEs in the north east of England: A multi-perspective framework. Journal of Enterprise Information Management, 26, 250-275.

Armbrust, M., Fox, A., Griffith, R., Joseph, A.D., Katz, R., Konwinski, A., \& Zaharia, M. (2010). A view of cloud computing. Communication of the $A C M, 53(4), 50-58$.

Asia Cloud Computing Association. (2015). The Asia Pacific cloud computing attractiveness index 2015. Philippines: Asia Cloud Computing Association. Retrieved from http://www.asiacloudcomputing.org/research/ smecloud2015

Cegielski, C.G., Jones-Farmer, L.A., Wu, Y., \& Hazen, B.T. (2012). Adoption of cloud computing technologies in supply chains: An organizational information processing theory approach. The International Journal of Logistics Management, 23(2), 184-211. 
Chin, W.W. (1998). Issues and opinions on structural equation modelling. MIS Quarterly, 22(1), vii-xvi.

Choudhary, V., \& Vithayathil, J. (2013). The impact of cloud computing: Should the IT department be organized as a cost center or a profit center? Journal of Management Information Systems, 30(2), 67-100.

Cohen, J. F., Mou, J., \& Trope, J. (2014). Adoption of cloud computing by South African firms: The role of institutional forces, absorptive capacity, and top management. Paper presented at the Proceedings of the Southern African Institute for Computer Scientist and Information Technologists Annual Conference 2014 on SAICSIT 2014 Empowered by Technology. Retrieved from http://dl.acm.org/citation.cfm?id=2664604

Fornell, C., \& Larcker, D. F. (1981). Evaluating equation models with unobservable variables and measurement error. Journal of Marketing Research, 18(1), 39-50.

Galligan, J., \& Mansor, D. (2011). Cloud computing for SMEs in Malaysia: Unlocking the potential of cloud computing for a new world of business. myForesight, 32-33.

Gangwar, H., Date, H., \& Ramaswamy, R. (2015). Developing a cloudcomputing adoption framework. Global Business Review, 16(4), 632-651.

Grandon, E. E., \& Pearson, J. M. (2004). Electronic commerce adoption: An empirical study of small and medium US businesses. Information \& Management, 42(1), 197-216.

Gupta, P., Seetharaman, A., \& Raj, J. R. (2013). The usage and adoption of cloud computing by small and medium businesses. International Journal of Information Management, 33(5), 861-874.

Gutierrez, A., Boukrami, E., \& Lumsden, R. (2015). Technological, organisational and environmental factors influencing managers' decision to adopt cloud computing in the UK. Journal of Enterprise Information Management, 28(6), 788-807. doi:10.1108/JEIM-01-2015-0001

Hair, J. F., Black, W. C., Babin, B.J., Anderson, R.E., \& Tatham, R.L. (2005). Multivariate data analysis (6th ed). Upper Saddle River, NJ: Pearson Prentice Hall. 
Hair, J., Money, A., Page, M., \& Samouel, P. (2007). Research methods for business. West Sussex: John Wiley \& Sons (UK).

Hassan, H., \& Ismail, N.A. (2015). Cloud computing: Use and impact of technology. Paper presented at the $5^{\text {th }}$ International Conference on Computing and Informatics (ICOCI) 2015, Istanbul, Turkey.

Hsu, P. F., Ray, S., \& Li-Hsieh, Y. Y. (2014). Examining cloud computing adoption intention, pricing mechanism, and deployment model. International Journal of Information Management, 34(4), 474-488.

Iacovou, C. L., Benbasat, I., \& Dexter, A. S. (1995). Electronic data interchange and small organizations: Adoption and impact of technology. MIS Quarterly, 465-485.

Igbaria, M., Zinatelli, N., Cragg, P., \& Cavaye, A. L. M. (1997). Personal computing acceptance factors in small firms: A structural model. MIS Quarterly, 279-305.

Lian, J., Yen, D.C., \& Wang, Y. (2014). An exploratory study to understand the critical factors affecting the decision to adopt cloud computing in Taiwan hospital. International Journal of Information Management, 34(1), 28-36.

Low, C., Chen, Y., \& Wu, M. (2011). Understanding the determinants of cloud computing adoption. Industrial Management \& Data Systems, 111(7), 1006-1023.

Mell, P., \& Grance, T. (2009). The NIST definition of cloud computing. National Institute of Standards and Technology, 53(6), 50.

Money, W., \& Turner, A. (2005). Assessing knowledge management system user acceptance with the technology acceptance model. International Journal of Knowledge Management, 1(1), 8-26.

Oliveira, T., \& Martins, M.F. (2010). Understanding e-business adoption across industries in European countries. Industrial Management \& Data Systems, 110(9), 1337-1354.

Oliveira, T., Thomas, M., \& Espadanal, M. (2014). Assessing the determinants of cloud computing adoption: An analysis of the manufacturing and services sectors. Information \& Management, 51(5), 497-510. 
Premkumar, G. (2003). A meta-analysis of research on information technology implementation in small business. Journal of Organizational Computing and Electronic Commerce, 13(2), 91-121.

Raymond, L. (2001). Determinants of web site implementation in small businesses. Internet Research, 11(5), 411-424.

SME Annual Report 2013/14. Retrieved from http://www.smecorp.gov.my/ vn $2 /$ node $/ 586$

Tornatzky, L. G., \& Fleischer, M. (1990). The process of technological innovation. Lexington, MA: Lexington Books.

Yigitbasioglu, O. (2014). Modelling the intention to adopt cloud computing services: A transaction cost theory perspective. Australasian Journal of Information Systems, 18(3), 193-210.

Yigitbasioglu, O.M. (2015). The role of institutional pressures and top management support in the intention to adopt cloud computing solutions. Journal of Enterprise Information Management, 28(4), 579594. http://dx.doi.org/10.1108/JEIM-09-2014-0087

Zhu, K., Dong, S., Xu, S. X., \& Kraemer, K. L. (2006). Innovation diffusion in global contexts: Determinants of post-adoption digital transformation of European companies. European Journal of Information Systems, 15(6), 601-616. 